\title{
THE MECHANISM OF CONTRE-COUP INJURY
}

\author{
BY
}

\section{A. F. GOGGIO}

From Division of Neuropathology, University of Toronto, Canada

(RECEIVED 30TH SEPTEMBER, 1940)

WHEN one considers the various types of intracranial lesion produced by trauma to the head-extradural hæmorrhage, subdural hæmorrhage, cortical laceration, hæmorrhage into brain substance or ventricles - there is one type of injury which of recent years has excited much speculation as to the mechanism of its causation, namely, " contre-coup injury."

It has long been observed in persons who have died as a result of trauma to the head and have come to autopsy that gross damage to brain tissue most frequently occurred, not in the situation immediately underlying the area of skull at which the traumatic force was applied, but rather at the pole of the brain diametrically opposite to the point struck. Thus, for example, a blow impinging on the skull in the region of the occiput might in some cases cause

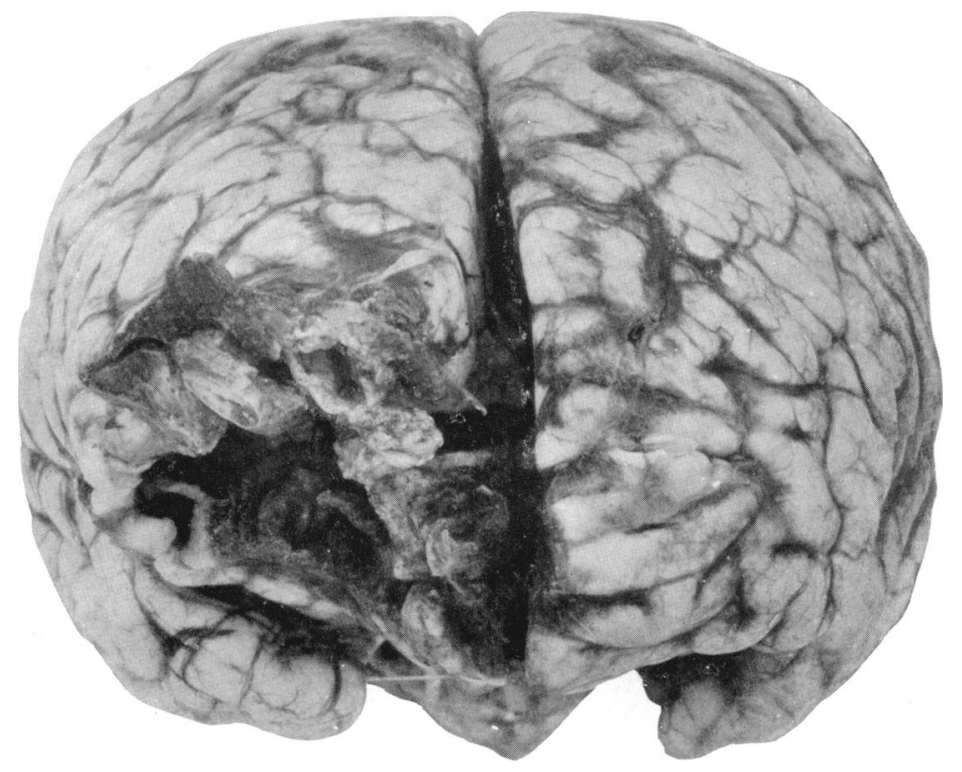

Fig. 1.-Severe contre-coup traumatic cortical laceration and hæmorrhage of the right frontal pole following a blow in the left occipital region. In this case right craniotomy was performed prior to death and a certain amount of completely " pulped " brain tissue sucked out from frontal area-this being responsible for part of the actual defect seen. 
some gross damage to the cortex of the brain immediately underlying the occiput, but the main cortical damage almost invariably would be sustained by the frontal and temporal poles diametrically opposite. Such is the injury referred to as contre-coup.

An illustration of a severe case of such contre-coup injury is given in Figs. 1 and 2. The arrow indicates the direction and area of application of the traumatic force.

Although contre-coup traumatic laceration is possible in head injuries in all planes, frontal contre-coup caused by occipital injuries, which is by far the most common and extensive, will be taken as a type for the purpose of this paper.

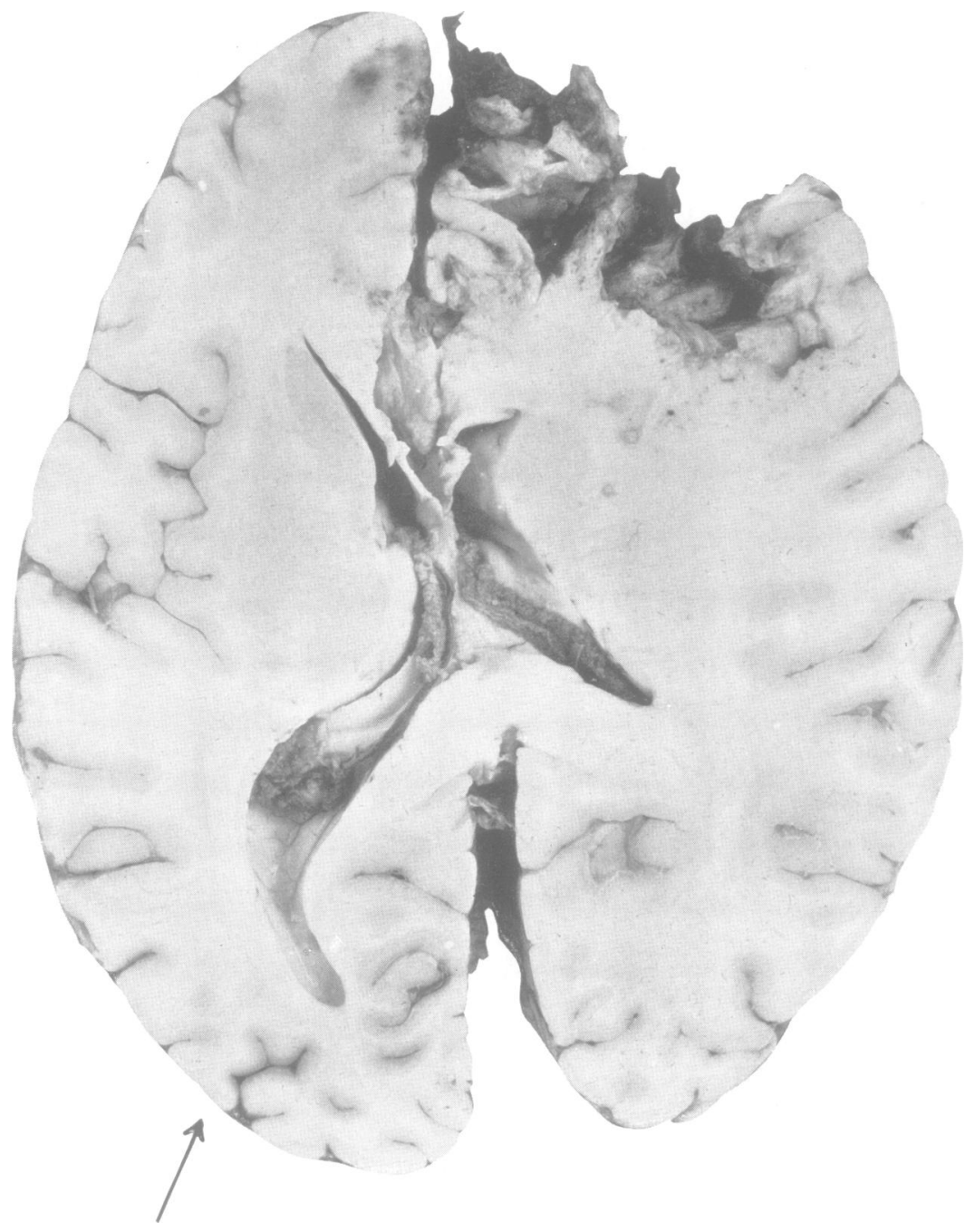

Fig. 2.- Horizontal section through the cerebral hemispheres cut through the area of contrecoup injury seen in Fig. 1. This shows the depth of the injury and the severe oedema of the right cerebral hemisphere. 
If we consider a statistical analysis of the intracranial lesions found at autopsy in cases of traumatic head injury, we find figures such as the following: Martland and Beling (1929) reviewed 309 such cases, and found that of these 309 cases 177 , or 57 per cent., showed contre-coup cortical laceration, while only 47 , or 16 per cent., showed " direct" cortical laceration. In a small series of 33 cases reviewed at the Banting Institute, Toronto, 14 showed contre-coup cortical laceration. Such figures seem to indicate that contre-coup injury is the most constant finding in cases of severe traumatic injury to the head. Thus, contre-coup is not only interesting but important (Fig. 3).
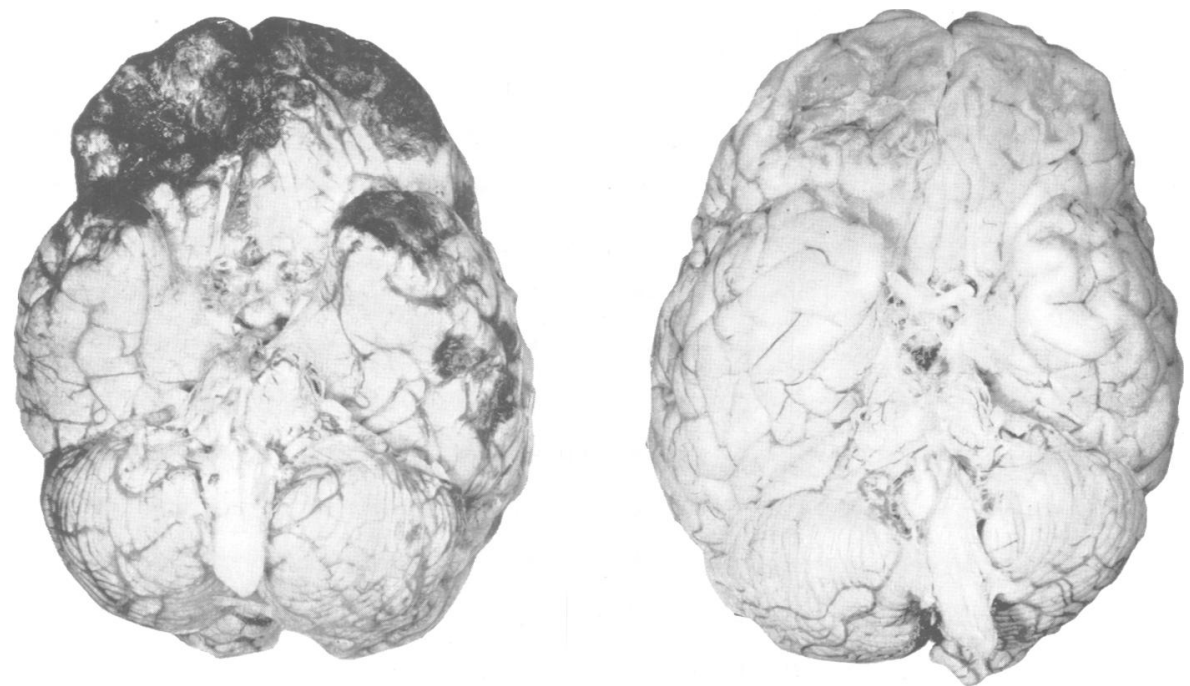

Fig. 3.-The bases of the brains of two patients, each of whom had received a blow on the left side of the back of the head. The brain on the left shows typical recent contre-coup damage of the frontal and temporal poles, more marked on the right. The old, healed contre-coup lesion seen in the brain on the right was the result of a blow which the patient received eight years before his death.

\section{Anatomical and Pathological Considerations}

Before going on to a discussion of how these contre-coup injuries might be produced, it is well to review a few anatomical and pathological features of importance, which are illustrated in Figs. 4 and 5.

The skull in which the brain is encased has several interesting features:

(a) It is composed of many separate bones, separated by suture lines which gradually fuse from youth to very old age to form a rigid brain case.

(b) The floor of this " brain case" is reinforced by thickenings and ridges of bone which might be considered as buttresses resisting deformation of skull (Fig. 4).

(c) The skull has various foramina, the most important of which are the foramen magnum and the jugular foramina situated rather posterior to the centre of the base of the skull (Fig. 4).

The various structures which envelop the brain within the skull must be considered: The tough dura mater separated by a film of synovial-like fluid 
from the underlying more delicate arachnoid membrane which bounds the subarachnoid space in which cerebrospinal fluid circulates and from which the blood vessels of the brain enter its tissues. The arachnoid membrane is attached to the pia mater, a thin and delicate membrane adherent everywhere to the surface of the brain, by fibrous trabeculæ which traverse the subarachnoid

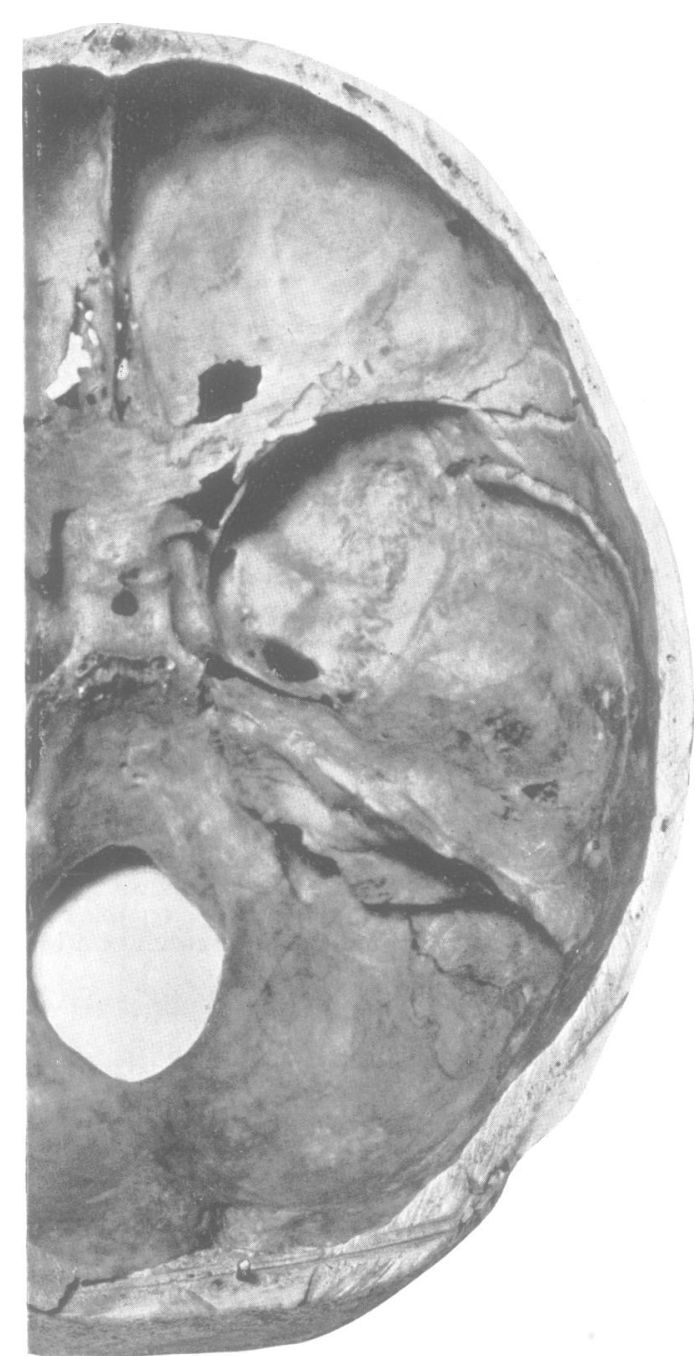

Fig. 4.-The right half of the base of the skull to show, in particular, the reinforcing bony buttresses.

space (Fig. 5). In the brain itself, we distinguish the cortex of the brain, with its large blood supply, from the underlying white matter, with its relatively less abundant blood supply.

When we consider the pathology of contre-coup injury we observe that it appears to be essentially a hæmorrhagic phenomenon. There is hæmorrhage 
from the small blood vessels in the superficial layers of the cortex of the affected region of the brain. These may be merely " ring" or " streak" hæmorrhages into the Virchow-Robin spaces and capillary fields of the small vessels of the cortex, these hæmorrhages having a tendency to occur toward the summits of the convolutions. On the other hand, the hæmorrhage may be so severe that quite extensive areas of cortex are literally " torn to pieces " and converted into a bloody pulp, filling a cavity in the brain tissue which may extend quite deep into the underlying white matter (Fig. 2), and which is bounded by tissue showing the smaller hæmorrhages described and having a ragged and lacerated surface. The subarachnoid space is locally filled with extravasated blood and bits of avulsed brain tissue and the whole cerebrospinal fluid is rendered bloody. Such severe damage probably develops gradually by an oozing of blood from ruptured small vessels over some period of time.

In Fig. 6, drawn from a miscroscopical section of a case of contre-coup

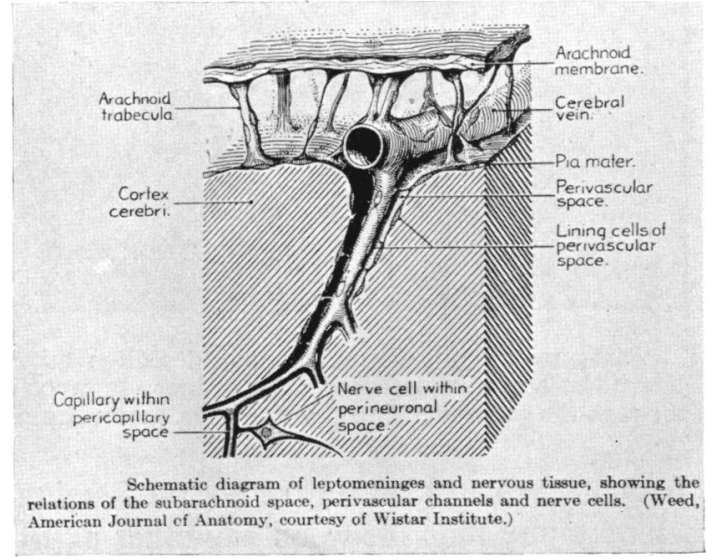

Fig. 5.-Schematic diagram of leptomeninges and nervous tissue, showing the relations of the subarachnoid space, perivascular channels and nerve-cells. (Weed, American Journal of Anatomy, courtesy of Wistar Institute.)

laceration, an attempt is made to illustrate graphically what we believe to be the essential lesion in contre-coup injury. It is meant to stress the idea, not universally accepted, that the primary hæmorrhage is intracortical.

\section{Theories as to Mechanism by which Contre-coup Injury is Produced}

On first being confronted with the fact of contre-coup injury, there is a tendency to seize upon one of the " simple explanations" given for its production and to accept it as the "cause" of the phenomenon. But when one stops to consider the many possible factors which may play a part in the production of contre-coup brain injury, the problem assumes very real complexity. It is intended here to discuss briefly these factors, and to present several new conceptions which make for interesting speculation.

Concerning the type of blow which causes contre-coup injury, we have little 
to say except that, in our observation and in that of others, contre-coup is more liable to be produced by a "heavy" blow of some duration applied over a fairly large area of the skull than by a sharp blow to a small area which has a greater tendency to cause a depressed fracture of the skull. It would appear that falls and vehicular accidents, where the moving head is arrested by a large resistant object, are especially conducive to contre-coup injury. Much more

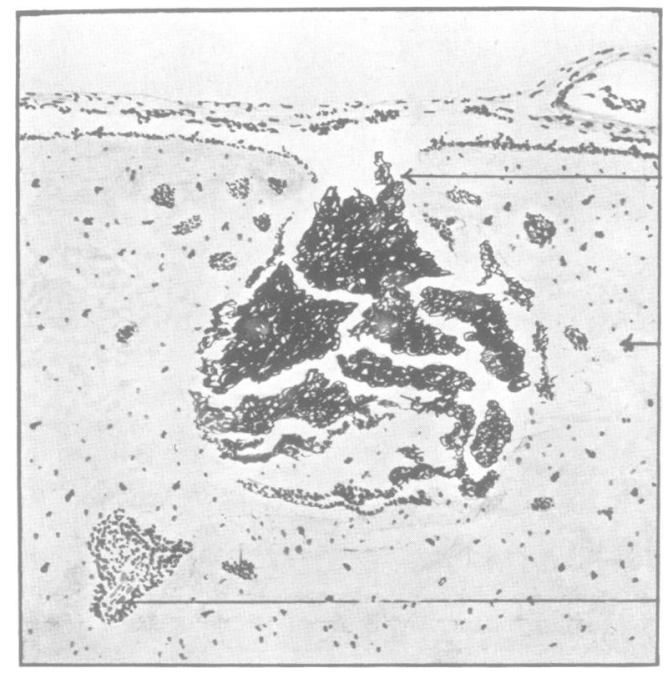

Fig. 6.-Drawing of a low-power view of a microscopical section taken from an area of contre-coup cortical laceration and hæmorrhage. The primary intracortical hæmorrhage is seen to have broken through the pia mater into the overlying subarachnoid space.

definite than this is the fact that blows on the occipital region are more liable to produce contre-coup injury than blows on any other part of the head.

But how does such a blow act upon the head to produce this contre-coup injury? Cassasa (1924) sought to explain the phenomena of concussion and cerebral contusion with production of " ring" hæmorrhages, which we have mentioned, mechanically by the forceful driving of cerebrospinal fluid from the subarachnoid space into the perivascular and perineural spaces (Fig. 5) This suggestion would enter into any consideration of the immediate cause of the pathological changes seen in cerebral contusions but it really does not bear on the problem of how the contre-coup phenomenon occurs.

\section{A. When the Skull is struck is it deformed, and if so, is this the Significant Factor?}

A 1. We might first postulate a simple "compression wave" theory which states, with truth, that when a force is applied which acts for an extremely short time fluids are not entirely incompressible (witness the conduction of sound by compression wave in water). Accordingly, when the skull is struck, the area struck is deformed or pushed inward on the underlying cortex (Fig. 7). Since this cortex is supported by other "compressible" nervous tissue beyond 
it, the blow on the underlying cortex is, as it were, " cushioned," and a wave of compression passes through the brain tissue toward the opposite side of the skull. When the compression wave reaches the cells of the cortex at the opposite side, these cells are suddenly thrown upon an unyielding surface, the skull, hence are damaged by the impact.

This theory is given as one way of describing the idea, perhaps most prevalent of all, that contre-coup injury is due to some form of "rebound " of the brain away from the part of the skull which is struck to the opposite side. It has the objection that the traumatic force should be greater at the point of application of the blow than at any other part, either coincidently or subsequently.

A 2. We might next postulate, by way of modification, an " elastic body" theory: Recently it has been shown by high-speed photography that when elastic bodies of various types, from golf balls and footballs to balls of steel, are struck they are deformed. They are deformed not only at the point struck but as a whole, and pass through changes in shape somewhat as is diagramatically represented in Fig. 7. It might be reasonable to suppose that the
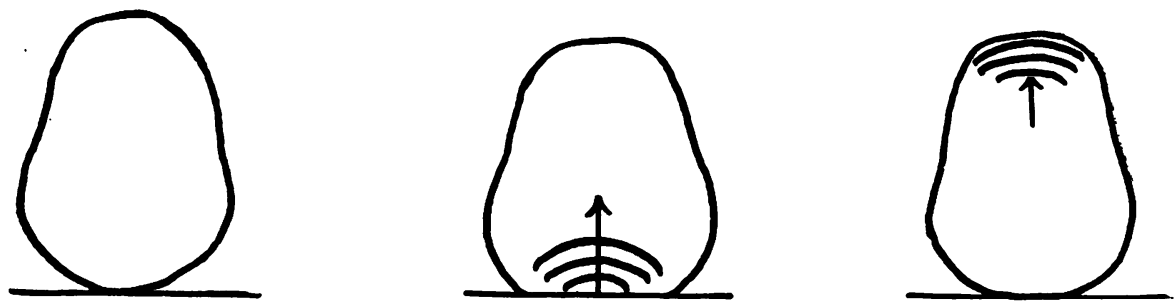

A 1. "Compression Wave" or "Rebound" theory-deformation of skull at point of impact.
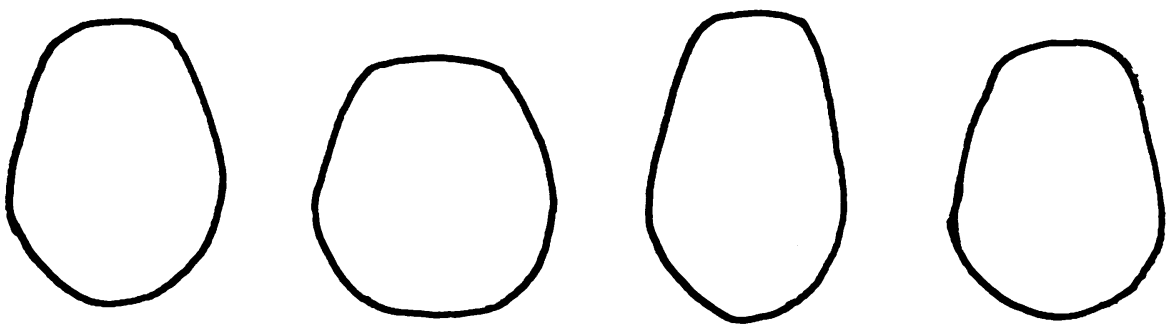

A 2. Elastic body theory-changes in shape of skull as a whole.

Fig. 7.-Diagrams to illustrate possible types of deformity of the skull at the moment of the blow.

skull should so behave, and that the sudden changes in position of the opposite side of the skull, perhaps meeting a compression wave transmitted through the brain tissue at different velocity and in an " out of phase " manner, might well produce injury at the opposite pole. Against this theory are, I believe, the composite anatomical structure of the skull, with its sutures and buttresses, and the fact that contre-coup will occur when fracture is present, for fracture of the skull theoretically should prevent these elastic changes in shape. The presence or absence of contre-coup in children and adolescents in whom the skull sutures are yielding might well be worth investigation from this point of view. 
In its support we have the consideration that if such elastic vibrations occur they will tend to be most marked in amplitude on the unsupported side, i.e. in the region of contre-coup, much as if a bar of an elastic metal is made to strike the floor on one end, the end against the floor will be maintained more or less stationary while the free end may vibrate freely.

\section{B. Do Differences in the Specific Gravity of the Intracranial contents play a significant rôle in Contre-coup Injury?}

W. Ritchie Russell (1932) has advanced an explanation of the production of contre-coup on this basis. He makes several preliminary statements bearing on the problem:

1. That the brain fits the skull accurately, and that this, in addition to allowing the skull to bear the brunt of the blow, allows the strain exerted by the traumatic force to be distributed to all parts of the intracranial contents.

2. That the brain substance has greater specific gravity than the cerebrospinal fluid or blood, and will, therefore, tend to displace the latter.

3. That there is present within the skull a subarachnoid space containing cerebrospinal fluid which is capable of enlargement by reason of that fluid.

4. That the skull must not be considered as a closed box, for the jugular veins and foramen magnum can allow exit of blood, cerebrospinal fluid, and brain itself from the interior of the skull.

5. That the brain, for the above reasons, is capable of limited movement within the skull.

Ritchie Russell's explanation is roughly this: When the motion of the skull is suddenly arrested the brain, by reason of its momentum, carries on in the original direction by displacing the cerebrospinal fluid between it and the arrested skull and by forcing venous blood out of the skull. This motion of the brain relative to the skull is obviously greatest at a point diagonally opposite the point of contact. Since the subdural space cannot open up to allow this motion, whereas the subarachnoid space can do so by virtue of inflow of cerebrospinal fluid, there occurs a tearing-away of the brain from its trabecular attachments to the arachnoid membrane, which results in rupture of the small blood vessels running in the subarachnoid space and pia mater and entering the cortical substance. Thus, Ritchie Russell considers that in contre-coup injury the primary occurrence is a subarachnoid hæmorrhage and that the blood liberated from the torn vessels secondarily extends into the brain substance from its surface, causing destruction of cortical tissue.

Ritchie Russell's explanation is in many ways an attractive one, but it has several serious objections. First, there is the fact that in our observations (and, I believe, in that of Rand and Courville), the primary hæmorrhage in contre-coup injury is not subarachnoid but rather intracortical in position (Fig. 6). Observation of an area of mild contre-coup injury in the gross may not show any subarachnoid hæmorrhage. Secondly, the differences in specific gravity are so small and the time of action of the arresting force so short that it is highly unlikely that such displacement of cerebrospinal fluid as suggested 
could occur. Thirdly, because fluids are relatively incompressible, unless the actual volume of the cranial cavity is changed no fluid could leave the skull under such an impact unless something of equal volume entered the skull coincidently.

\section{The "Pressure Gradient" Theory}

This theory differs from the others in that it deals entirely with pressure changes which occur within the skull whenever the moving skull is suddenly arrested in its motion or whenever the skull receives a heavy blow. It attempts to treat contre-coup as a problem in hydrodynamics, which may be simplified as follows (see accompanying diagram, Fig. 8).

$$
\begin{gathered}
\text { MOMENTUM } \\
=\text { MASS } x \text { VELOCITY }
\end{gathered}
$$

DENSITY $\times$ VOLUNE $x$ VELOCITY

$=\beta \times(\alpha \times D) \times V$

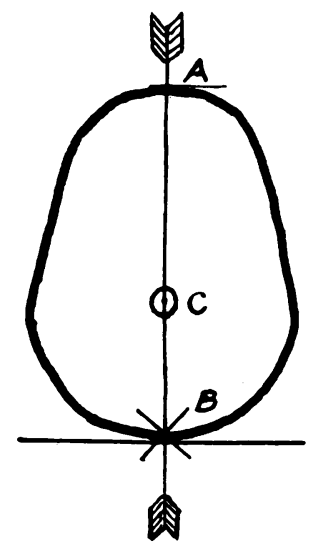

Pressure $x$ Time

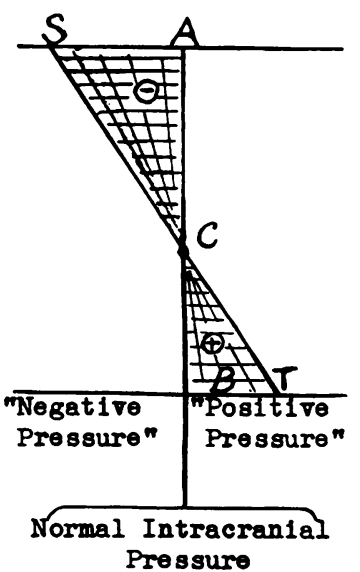

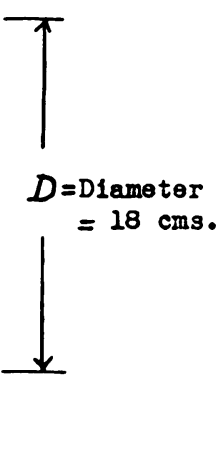

$$
\begin{gathered}
P \times T \\
=(P \times \propto)
\end{gathered}
$$

$\mathrm{H}=$ Distance of fall $=9 \mathrm{ft}$.

$g=$ Acceleration due to gravity $=32 \mathrm{ft}$. sec. sec.

$\mathrm{V}=$ Velocity at moment of impact

$\mathrm{V}^{2}=2 \mathrm{gH}=2 \times 32 \times 9$

$\mathrm{V}=\sqrt{2} \overline{\mathrm{gH}}=\sqrt{2 \times 32 \times 9}=24 \mathrm{ft}$. sec.

$\therefore$ Velocity $=24 \mathrm{ft}$. $/ \mathrm{sec} .=720 \mathrm{~cm}$. $/ \mathrm{sec}$.

$\ddot{\mathrm{T}}=\frac{1}{10}$ sec. $=$ time of action of arresting force.

$a=$ Area of cross section of cylinder

$\beta=1 \cdot 040=$ density of brain tissue

$\mathrm{D}=$ Diameter of skull $=18 \mathrm{cms}$.

\section{Equating :-}

Force $\times$ Time $=$ Momentum

$\mathrm{P} \times \boldsymbol{a} \times \mathrm{T}=\beta \times a \times \mathrm{D} \times \mathrm{V}$

$\mathrm{P} \times \frac{1}{10}=1.040 \times 18 \times 720$

$\mathrm{P} \quad=1.040 \times 18 \times 720 \times 10$ dynes $/ \mathrm{sq} . \mathrm{cm}$

$\therefore$ Pressure $=1.040 \times 18 \times 720 \times 10 \times 1 / 980 \mathrm{~cm}$. of $\mathrm{H}_{2} \mathrm{O}$

$=1,375 \mathrm{~mm}$. of $\mathrm{H}_{2} \mathrm{O}$

ST Indicates pressure gradient

Fig. 8.-Diagram illustrating the principles involved in the "pressure gradient" theory of the author. 
Let us consider the skull as an incompressible shell, $\mathrm{AB}$, filled with semifluid brain tissue with a communication to the exterior (the foramen magnum and jugular foramina) at $\mathrm{C}$. Let us suppose it falls freely from a height $\mathbf{H}$ and is arrested by a resistant object in time $\mathrm{T}$. Then, velocity at time of impact, $\mathrm{V}=\sqrt{2 g \mathrm{H}}$, where $g$ is acceleration due to gravity and $\mathrm{H}$ is distance of fall. This falling object has momentum by virtue of its weight and velocity.

Again, for simplicity, we need not consider the whole object but merely a cylindrical core of cross-sectional area $a$ extending between A and B. The momentum of this cylinder will be equal to its mass $\times$ its velocity, i.e. its density $\times$ its volume $\times$ its velocity. At the instant of impact this momentum is counteracted by an arresting force acting on the cylinder between A and B, which we may measure as a pressure $\mathbf{P}$ per sq. $\mathrm{cm}$. acting over a cross-sectional area $a$. This force, $\mathbf{P} \times a$, acts for a time $\mathrm{T}$, which it requires to nullify the momentum of the falling cylinder.

We may equate these:

arresting force $\times$ time $=$ momentum of cylinder, or $\mathrm{P} \times a \times \mathrm{T}=$ density $\times$ volume $\times$ velocity of cylinder.

Let us now substitute estimated values for these symbols as follows:

Let $\mathbf{H}=$ distance of fall $=\mathbf{9} \mathrm{ft}$.

$g=$ acceleration due to gravity $=32 \mathrm{ft} . / \mathrm{sec} . / \mathrm{sec} .=980 \mathrm{~cm} . / \mathrm{sec} . / \mathrm{sec}$.

$\mathrm{V}=$ velocity at moment of impact $=\sqrt{2 g \mathrm{H}}=24 \mathrm{ft}$. $/ \mathrm{sec}$. or $720 \mathrm{~cm} . / \mathrm{sec}$.

$\mathrm{T}=$ time of action of arresting force $=\frac{1}{10} \mathrm{sec}$.

$a=$ cross-sectional area of hypothetical cylinder.

$\beta=$ density of brain tissue $=1.040$ grams.

$\mathrm{D}=$ diameter of skull $=$ distance between $\mathrm{A}$ and $\mathrm{B}=18 \mathrm{~cm}$.

Then, continuing our equation:

$\mathrm{P} \times a \times \mathrm{T}=$ density $\times$ volume $\times$ velocity of cylinder $=\beta \times(\alpha \times \mathrm{D}) \times \mathrm{V}$.

$\mathrm{P} \times \mathrm{T}=\beta \times \mathrm{D} \times \mathrm{V}$

$\mathrm{P} \times \frac{1}{10}=1.040 \times 18 \times 720$

$\mathrm{P}=1.040 \times 18 \times 720 \times 10$ dynes/sq. $\mathrm{cm}$.

$=\frac{1.040 \times 18 \times 720 \times 10 \mathrm{~cm}}{980}$ of water $=137.5 \mathrm{~cm}$. of water.

Pressure $=P=137.5 \mathrm{~cm} . \mathrm{H}_{2} \mathrm{O}=10 \cdot 1 \mathrm{~cm} . \mathrm{Hg}$.

$$
=1375 \mathrm{~mm} . \mathrm{H}_{2} \mathrm{O}=101 \mathrm{mms} \text {. Hg., approx. }
$$

As we have intimated, this pressure $\mathbf{P}$ is distributed through the brain tissue (of the hypothetical cylinder) in the nature of a pressure gradient with the maximum pressure at $\mathrm{B}$ and the minimum pressure at $\mathrm{A}$, for every particle contained in the cylinder must be acted upon by the arresting force.

The absolute pressure at any point will depend on the position of $\mathrm{C}$, the communication with external pressure. If this is midway between $\mathrm{A}$ and $\mathrm{B}$ the pressure at B will be increased by $675 \mathrm{~mm}$. of $\mathrm{H}_{2} \mathrm{O}$, while the pressure at $\mathrm{A}$ is diminished by $675 \mathrm{~mm}$. of $\mathrm{H}_{2} \mathrm{O}$. If $\mathrm{C}$ is nearer to $\mathrm{B}$ than it is to $\mathrm{A}$ then the pressure at $\mathrm{B}$ is increased by less than this amount and the pressure at $\mathrm{A}$ 
diminished by more than this amount. Thus, in the common occipito-frontal type of contre-coup, if $\mathrm{AC}=2 \times \mathrm{CB}$, then pressure at $\mathrm{A}$ would be diminished by $920 \mathrm{~mm} . \mathrm{H}_{2} \mathrm{O}$, while pressure at B is increased by $460 \mathrm{~mm} . \mathrm{H}_{2} \mathrm{O}$ pressure. (See diagram of pressure gradient, Fig. 8.)

Thus, if we accept the simplifying assumption made, we may conclude that when a man's head falls $9 \mathrm{ft}$. under the action of gravity and is arrested in onetenth of a second, or when it falls a lesser distance and " bounces," or when a man's head travelling at 16 miles per hour is arrested in one-tenth of a second, a pressure gradient is set up momentarily with the skull of the order of magnitude of $1,375 \mathrm{~mm}$. of water with a maximum fall of pressure at the point of brain surface diametrically opposite to the point of application of the force, that is, in the area of contre-coup of $675 \mathrm{~mm}$. of water or more $(50 \mathrm{~mm}$. mercury or more). It is to be noted that this pressure fall will be greatest in the occipitofrontal type of trauma which we have shown has by far the highest incidence of contre-coup.

The severity of the pressure gradient will be modified in the actual case by the possibility of actual skull deformity and by the fact that the foramen magnum and jugular foramina do not communicate directly with the outside air (but venous sinuses are at atmospheric pressure).

Here, then, is a dramatic intracranial event occurring at the moment of impact of a traumatic force to the head. Is it the cause of contre-coup hæmorrhage? Fortunately for the individual these changes in pressure will tend to occur in all the intracranial contents coincidently, and will, therefore, involve the blood in the blood vessels coincidently with the surrounding tissues. But, on the other hand, these blood vessels contain a fluid which is circulating and which is constantly under the pressure of a force pump which is itself not influenced at all by these changes inside the skull. It is, therefore, conceivable that a pressure imbalance is momentarily set up and that the small blood vessels in the area of contre-coup are distended and ruptured by a sudden release of external pressure which is not completely met by a fall in intravascular pressure due to circulatory inflow from an outside pressure source, the contraction of the left ventricle of the heart.

\section{Do Rotation Effects play a part in the production of Contre-coup Injury?}

We have observed that the fronto-temporal region is the area of predilection for the occurrence of contre-coup. Here the irregular structure of the skull, particularly the orbital surface of the frontal bones and lesser wings of the sphenoids, contrast strongly with the smooth shelving surface in other parts. Damage here certainly seems to suggest movement of brain against the skull. There is a type of movement seldom mentioned, which may often occur, namely rotation. When a head is struck by a blow or a fall it is seldom struck squarely and a rotatory component is often present. Anyone who has rotated a glass of water and seen the water stand still while the glass rotates, will realize that such a phenomenon in operation in the skull might well cause damage to the brain in a region where body projections are present. 
The author wishes to express his appreciation to Dr. E. A. Linell, Professor of Neuropathology, University of Toronto, to whom he is very greatly indebted in the preparation of this paper. He also wishes to thank Professor J. L. Synge, of the Department of Applied Mathematics of the University of Toronto, for his assistance in the mathematical aspects of the problem.

\section{REFERENCES}

Cassasa, C. S. B. (1924). Proc. N.Y. path. Soc. (New Series), 25, 101.

Martland H.S. and Beling C. (1929). Arch. Neurol. Psychiat. Chicago. 22, 1001.

Russell, W. Ritchie. (1932). Brain. 55, 549. 